\title{
On the concept of third occipital headache
}

\author{
NIKOLAI BOGDUK, ANTHONY MARSLAND \\ From the Pain Clinic, Princess Alexandra Hospital, and the Department of Anatomy, University of Queensland, \\ Brisbane, Australia
}

SUMMARY One of the putatative causes of headache is osteoarthritis of the C2-3 zygapophysial joint. A technique for blocking the third occipital nerve which innervates this joint was devised and used as a screening procedure for headache mediated by this nerve. Seven out of ten consecutive patients presenting with suspected cervical headache were found to suffer pain mediated by the third occipital nerve and stemming from a C2-3 zygapophysial joint. Because third occipital headache may be indistinguishable clinically from tension or other forms of headache, third occipital nerve blocks are advocated as means of establishing this largely unrecognised diagnosis.

It is well recognised that disorders of the cervical spine can be a source of headache ${ }^{1-5}$ and one such disorder is said to be osteoarthritis of the upper cervical joints. ${ }^{1-7}$ The upper cervical joints consist of the atlanto-occipital joints, the median and lateral atlanto-axial joints, and the C2-3 zygapophysial joints, but in general, these joints have been implicated only collectively in the pathogenesis of headache. Seldom has the symptom of headache actually been ascribed to osteoarthritis specifically of one or other of these joints. In fact, no studies have demonstrated that osteoarthritis of the atlanto-occipital joints can be a cause of headache, while the median atlanto-axial joint has been implicated only on the basis of circumstantial radiological evidence. ${ }^{8}$ Furthermore, regardless of perhaps long-held convictions, explicit evidence demonstrating that headaches can be caused by osteoarthritis of the lateral atlanto-axial joints has only recently appeared. ${ }^{9}$

The C2-3 zygapophysial joints are a less familiar potential source of headache. Anatomically, these joints differ markedly from the other upper cervical synovial joints. Whereas the joints of the atlas lie ventral to the emerging spinal nerves, the C2-3 zygapophysial joints lie behind the intervertebral foramina in sequence with the other zygapophysial joints and are the highest synovial joints associated with an intervertebral disc at the same level. Moreover, functionally they represent a transition zone between the

Address for reprint requests: Dr $\mathbf{N}$ Bogduk, Department of Anatomy, University of Queensland, St Lucia, Queensland, 4067, Australia.

Received 2 April 1985 and in revised form 4 November 1985. Accepted 9 November 1985
C1-2 level, which accommodates rotation of the head, and the lower cervical spine, which accommodates flexion and extension of the neck. ${ }^{10}$

Our attention was drawn to the role of the C2-3 joints in the pathogenesis of headache by two clinical reports. Trevor-Jones ${ }^{11}$ reported three patients in whom he found the third occipital nerve to be entrapped by osteophytes from an arthritic C2-3 joint, and surgical release of the entrapment relieved their headaches. Maigne ${ }^{12}$ reported 98 patients whose headaches he successfully treated with periarticular injections of local anaesthetic and manipulation of the C2-3 joints. There are, however, certain limitations to these two reports. Interesting though his findings were, Trevor-Jones did not describe how patients with third occipital nerve entrapment could be identified pre-operatively. The limitation of Maigne's report is that he used particular injections without radiological control, so it could be questioned whether the relief he obtained was due to selective anaesthetisation of the C2-3 joint.

Notwithstanding these limitations, we were prompted by these reports and our awareness of the biomechanical vulnerability of the C2-3 zygapophysial joints to undertake a study of patients presenting with occipital or suboecipital headache, to test the hypothesis that their pain stemmed from the C2-3 zygapophysial joints. A previous anatomical study ${ }^{13}$ had demonstrated the nerve supply to the C2-3 zygapophysial joints and the topographical and radiological disposition of the third occipital nerve, and this information was used to perform radiologically controlled blocks of the nerves supplying the C2-3 zygapophysial joints in the patients selected for study. 


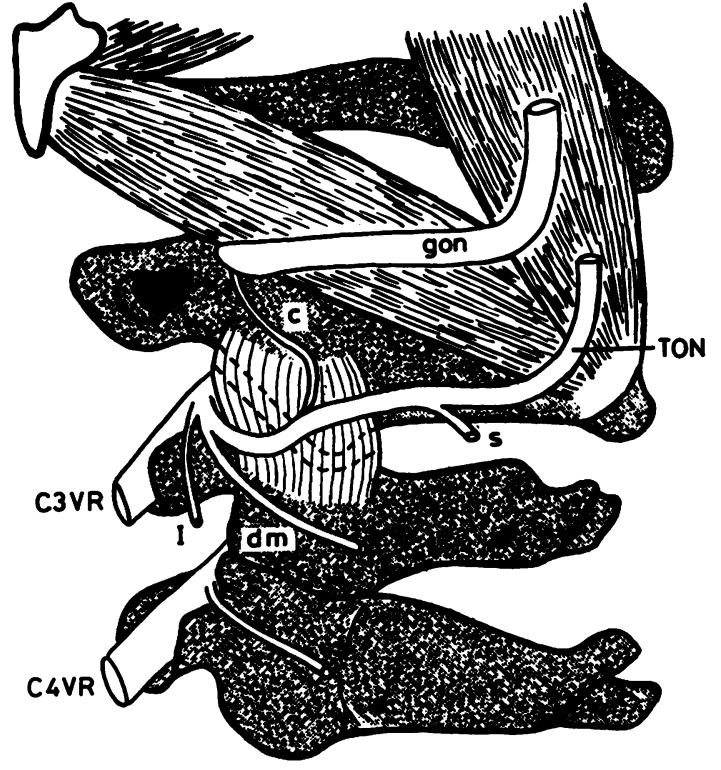

Fig 1 A sketch of a posterolateral view of the left third occipital nerve (TON) seen crossing the lateral aspect and then the dorsal aspect of the lower half of the C2-3 zygapophysial joint. A branch to semispinalis capitis ( $s$ ) arises from the nerve as it crosses the lamina of $C 3$ and before it turns dorsally to enter the skin. Articular branches to the joint arise from the deep aspect of the third occipital nerve or from the communicating loop (c) to the $C 2$ dorsal ramus. The greater occipital nerve (gon) is shown crossing the obliquus inferior and rectus capitis posterior major, and the lateral (l) and deep medial (dm) branches of the C3 dorsal ramus are shown crossing the $C 3$ transverse process. VR: ventral rami.

\section{Methods}

Ten consecutive patients presenting with occipital or suboccipital headache were studied. The headache history was recorded in terms of site, radiation, frequency etc, according to the protocol suggested by Lance. ${ }^{5}$ A physical examination was performed including a thorough examination of the neck for abnormalities of movement and tenderness. Signs particularly sought were tenderness over the cervical zygapophysial joints, which was adopted as a putatative sign of cervical arthropathy, and reproduction of head pain by sustained pressure over any site of tenderness.

All patients underwent diagnostic blocks of the third occipital nerve, ipsilateral to their complaint of pain, or bilaterally in cases of bilateral pain. Patients whose pain was relieved by blocking the third occipital nerve underwent two or more repeat blocks, at intervals between one week and one month, to confirm the response.

Because of ethical considerations, related mainly to the radiation exposure involved in performing fluoroscopically controlled blocks, formal control blocks were not routinely performed. However, certain control observations were made when the opportunity presented itself in the course of related investigations or procedures. These included blocks of lower cervical dorsal rami ${ }^{13}$ which were performed as a screening procedure for intercurrent neck pain; C2 ganglion blocks, ${ }^{14}$ which were performed to exclude headache mediated by the $\mathrm{C} 2$ spinal nerve; and in one case, an intramuscular injection of local anaesthetic, performed during an attempted intra-articular injection of steroids.

\section{Anatomy}

The $\mathrm{C} 3$ dorsal ramus is a short nerve that arises from the spinal nerve and passes backwards through the $\mathrm{C} 2-3$ intertransverse space where it divides into a lateral and two medial branches. The lateral branch supplies the more superficial posterior cervical muscles. ${ }^{13}$ The deeper of the two medial branches winds around the waist of the $\mathrm{C} 3$ articular pillar and enters the multifidus muscle. The superficial medial branch is known as the third occipital nerve. This nerve crosses the lateral and dorsal aspects of the lower half of the C2-3 zygapophysial joint (fig 1). It then passes across the lamina of $\mathrm{C} 3$ before turning backwards and upwards to pierce semispinalis capitis and splenius capitis to become cutaneous over the suboccipital area. Articular branches of the C2-3 zygapophysial joint arise from the deep aspect of the third occipital nerve as it crosses the joint, or from a communicating loop between the third occipital nerve and the $\mathrm{C} 2$ dorsal ramus, which crosses the dorsal aspect of the joint $^{13}$ (fig 1).

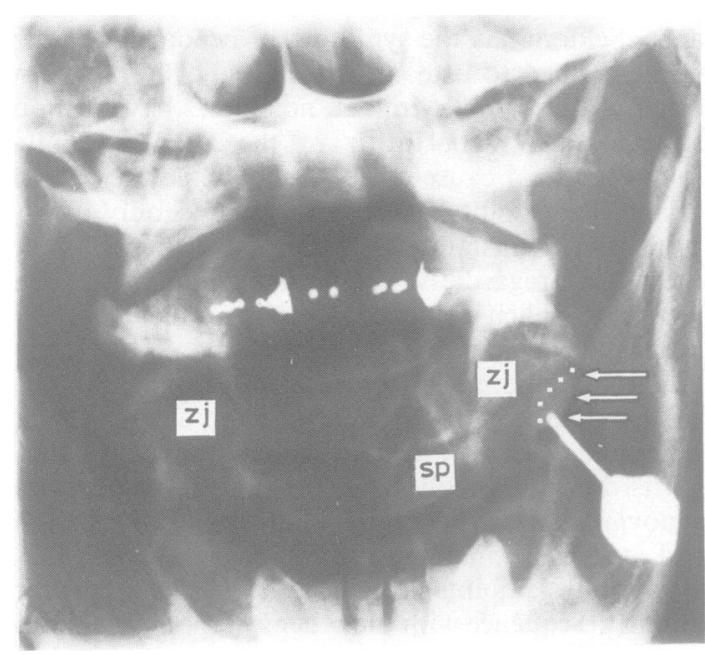

Fig 2 A postero-anterior radiograph of the C2-3 zygapophysial joints. The joints (zj) are seen as laterally convex silhouettes rising upwards from the concavity of the C3 articular pillar, opposite the level of the C2 spinous process (sp), and below the lateral atlanto-axial joints. The target region for third occipital nerve blocks is shown by dotted lines. A needle rests at the lowest of three sites for injection (arrows) along the lateral margin of the radiographic silhouette. 


\section{Radiology}

The constancy of the course of the third occipital nerve makes its location readily identifiable on postero-anterior radiographs. The proximal part of the nerve crosses the lower half of the silhouette of the C2-3 zygapophysial joint. This landmark is recognised as a convexity that rises upwards from the concavity of the $\mathrm{C} 3$ articular pillar, and usually lies horizontally opposite the level of the $\mathrm{C} 2$ spinous process and C2-3 disc space (fig 2). Because of the orientation of the joint, a distinct joint space is not always visible in a postero-anterior view, and cannot be relied upon as a landmark. A needle introduced onto the lateral margin of the silhouette, between its mid-point and lower end, will reliably encounter the third occipital nerve proximal to the origin of articular branches to the $\mathbf{C} 2-3$ joint.

\section{Third Occipital Nerve Blocks}

Third occipital nerve blocks were performed using fluoroscopic control with the patient lying prone on a table, the chest supported by a pillow and the head supported by a firm sponge cushion, leaving the mouth unobstructed. The C2-3 zygapophysial joint was visualised on the fluoroscope by appropriately adjusting the head tilt and opening the mouth.

Once adequate orientation was achieved, the skin of the back of the neck was prepared as for an aseptic procedure and a puncture site was selected over the posterolateral aspect of the neck at the level of the $\mathrm{C} 2$ spinous process. The puncture site was determined radiographically by adjusting the position of the point of the needle on the skin so that its radiographic projection lay just lateral to the silhouette of the $\mathrm{C} 2-3$ joint. $A 22$ gauge, $70 \mathrm{~mm}$ needle was then inserted through the puncture site and directed ventrally and slightly medially into the neck muscles. The course of the needle, as it was advanced through the muscles, was repeatedly checked fluoroscopically, every 1 to $2 \mathrm{~cm}$, to ensure that it travelled towards the back of the C2-3 joint. The dorsal aspect of the joint was the initial target in order to ensure the proper depth of insertion. Bony resistance coupled with the projection of the needle's point over the joint indicated that it lay dorsal to the joint, and had not been misdirected ventrally in front of the joint. Once bone had been contacted, the needle was withdrawn slightly and readjusted laterally until its tip lay on the lateral margin of the silhouette (fig 2), all adjustments being monitored by repeated screening. Proper location of the point of the needle was confirmed radiographically and by the sensation that it rested on bone. That it lay on the very lateral margin of the joint was confirmed by adjusting the needle slightly more laterally to feel it slip ventrally off the margin. It was then repositioned.

To block the third occipital nerve, three injections of $0.5 \mathrm{ml}$ of $0.5 \%$ bupivicaine were performed: one at the midpoint of the convexity of the silhouette, one at its lower end, and the last between these two. Three such injections thoroughly bracket the course of the nerve, and the small volume used, while adequate to block the target nerve, minimised possible spread to adjacent levels. At the end of the procedure, the adequacy and accuracy of the block was confirmed clinically by examining for anaesthesia in the cutaneous distribution of the third occipital nerve.

\section{Results}

The essential clinical features of the patients studied are summarised in the table. All complained of occipital and suboccipital headache associated with pain radiating to the forehead or related regions. All had at least one feature that could be construed as suggesting a cervical origin for their pain such as a history of neck injury, precipitation of pain by neck movement, or cervical tenderness. Only one patient (number 11) suffered the associated features of photophobia, nausea and vomiting that strongly suggested a diagnosis of common migraine. Otherwise, the clinical features of the patients studied did not conform to those of any conventional diagnostic category,

able Clinical features

\begin{tabular}{|c|c|c|c|c|c|c|c|c|c|c|c|}
\hline 'atient & Sex & $\begin{array}{l}\text { Age } \\
(y r)\end{array}$ & Onset & History & Site & Radiation & Quality & Frequency & $\begin{array}{l}\text { Aggravating } \\
\text { factors }\end{array}$ & Tender & $\begin{array}{l}\text { Restricted } \\
\text { movements }\end{array}$ \\
\hline $\begin{array}{l}1 \\
2 \\
3 \\
4 \\
5 \\
6 \\
7 \\
8 \\
9 \\
9\end{array}$ & $\begin{array}{l}\mathbf{M} \\
\mathbf{F} \\
\mathbf{F} \\
\mathbf{F} \\
\mathbf{F} \\
\mathbf{F} \\
\mathbf{F} \\
\mathbf{M} \\
\mathbf{M} \\
\mathbf{M}\end{array}$ & $\begin{array}{l}46 \\
53 \\
28 \\
31 \\
43 \\
30 \\
34 \\
52 \\
52 \\
29\end{array}$ & $\begin{array}{l}\text { IA } \\
\text { S } \\
\text { MVA } \\
\text { S } \\
\text { S } \\
\text { MVA } \\
\text { MVA } \\
\text { S } \\
\text { S } \\
\text { S }\end{array}$ & $\begin{array}{l}3 \mathrm{yr} \\
2 \mathrm{yr} \\
6 \mathrm{~m} \\
15 \mathrm{yr} \\
12 \mathrm{yr} \\
3 \mathrm{yr} \\
12 \mathrm{yr} \\
24 \mathrm{yr} \\
20 \mathrm{yr} \\
20 \mathrm{yr}\end{array}$ & $\begin{array}{l}\text { LSO } \\
\text { O } \\
\text { SO } \\
\text { RO } \\
\text { O } \\
\text { RSO } \\
\text { RO } \\
\text { SO } \\
\text { SO } \\
\text { O }\end{array}$ & $\begin{array}{l}\text { L orbit } \\
\text { Orbits } \\
\text { Vertex } \\
\text { Vertex } \\
\text { Orbits } \\
\mathbf{R} \text { orbit } \\
\overline{\text { Orbits }} \\
\text { Whole head } \\
\text { Orbits }\end{array}$ & $\begin{array}{l}\text { Ache } \\
\text { Ache } \\
\text { Ache } \\
\text { Ache } \\
\text { Ache } \\
\text { Ache } \\
\text { Ache } \\
\text { Throb } \\
\text { Vice-like } \\
\text { Throb }\end{array}$ & $\begin{array}{l}\text { Constant } \\
\text { Constant } \\
\text { Constant } \\
\text { Constant } \\
\text { Constant } \\
\text { Daily } \\
\text { Constant } \\
\text { Constant } \\
\text { Constant } \\
\text { Constant }\end{array}$ & $\begin{array}{l}\text { Lifting } \\
\text { Neck extension } \\
\text { Neck flexion } \\
\text { Reading } \\
\overline{\text { Neck movements }} \\
\text { Neck movements } \\
\text { Stress } \\
\overline{\text { Neck movements }}\end{array}$ & $\begin{array}{l}\text { C2-3 } \\
\text { C2-3 } \\
\text { C2-3 } \\
\text { C2-3 } \\
\text { SO } \\
\text { C2-3 } \\
\text { Nausea, } \\
\text { vomiting } \\
\text { photophobia }\end{array}$ & $\begin{array}{l}\text { Fl, Ex, R Rot } \\
\overline{\text { Fl, Ex, Rot }}\end{array}$ \\
\hline
\end{tabular}

lotes: (1) The onset of headache is tabulated as spontaneous (S) or following an industrial accident (IA) or a motor vehicle accident (MVA). (2) The length f history is measured in years (yr) or months (m). (3) The principal site of pain is tabulated as suboccipital (SO) or occipital (O), prefixed by left (L) or right 2) as appropriate. (4) C2-3 refers to tenderness over the C2-3 zygapophysial joints. SO refers to tenderness in the suboccipital region. (5) Abbreviations used ir movements are flexion (Fl), extension (Ex) and rotation (Rot) prefixed by left (L) or right (R) as appropriate. (6) Patient number 10 exhibited no signs in le neck, but suffered nausea, vomiting and photophobia. 
apart from possible cervical headache or perhaps tension headache.

Seven of the ten patients responded to unilateral diagnostic blocks of a third occipital nerve. The response was complete relief of all pain for the duration of action of the anaesthetic used, associated with the elimination of aggravating factors. Subsequent blocks reproduced exactly the same relief. Three patients (numbers 9, 10 and 11) had no relief following blocks of their third occipital nerves bilaterally. Nor was there any relief following blocks of either the $\mathrm{C} 4$ dorsal rami or the $\mathrm{C} 2$ ganglia.

Control observations corroborated the response in patients 1, 2, 5, 6 and 7. Patient number 1 underwent blocks of his C5, 6, 7 and C4 dorsal rami prior to third occipital nerve blocks. During none of these procedures did he report relief of his headache, but repeated blocks of his third occipital nerve consistently relieved his pain. This patient also underwent a single-blind investigation comparing the responses to short-acting (lignocaine) versus long-acting (bupivicaine) local anaesthetic. His headache was relieved for 1 hour after injection of lignocaine, but for 5 hours after using bupivicaine.

Patient number 2 underwent $\mathrm{C} 2$ ganglion blocks as her differential diagnosis included lateral atlantoaxial arthritis, but these did not relieve her headaches, whereas three blocks of her left third occipital nerve consistently relieved her headaches, as did similar blocks on three further occasions in the course of various therapeutic procedures.

Patient number 6 underwent blocks of her C5, 6 dorsal rami in the initial course of the investigation of her complaint of combined neck pain and headache. The C5, 6 blocks relieved her neck pain but did not influence her headaches. Reciprocally, the headaches, but not the neck pain, were repeatedly relieved by right third occipital nerve blocks.

Patient number 7 underwent a block of her right greater occipital nerve as her diagnosis included neuroma formation on this nerve, but this did not influence her constant aching headaches which, on the other hand, were relieved by third occipital nerve blocks.

During an unsuccessful attempt at injecting steroids into her right C2-3 zygapophysial joint, patient number 5 underwent an injection of local anaesthetic directed dorsal but superficial to the joint. This injection did not involve the third occipital nerve because no numbness ensued, and did not relieve her headache, but three effective blocks of the third occipital nerve, as evidence by numbness in the appropriate cutaneous field, succeeded in relieving her pain. Also, a single-blind block, using lignocaine instead of bupivicaine, had an appropriately shortened duration of relief.

\section{Discussion}

That patients with C2-3 zygapophysial arthropathy should suffer headache is not surprising. In the spinal cord, terminals of the C3 spinal nerve overlap with terminals of the trigeminal nerve, ${ }^{15-17}$ and the convergence between cervical and trigeminal afferents in the spinal grey matter provides a suitable neuroanatomical substrate for the referral of pain to the head.

Previous studies have shown that noxious stimulation of the muscles and ligaments innervated by the upper three cervical dorsal rami can produce headache in normal volunteers. ${ }^{18-20}$ The referral pattern of pain from cervical zygapophysial joints, however, has not been specifically studied, but such studies have been done in the lumbar region where zygapophysial pain can be referred to various regions of the lower limb. ${ }^{2122}$ Extrapolation of these results suggests that noxious stimulation of the upper cervical synovial joints could, like stimulation of the overlying muscles, cause headache.

Third occipital nerve blocks were adopted in this study because they provide a convenient means of screening for painful disorders mediated by this nerve. The structures innervated by the third occipital nerve are only skin, part of the semispinalis capitis muscle, and the $\mathrm{C} 2-3$ zygapophysial joint. ${ }^{13}$.There are no occult conditions of the skin, and no known conditions selectively affecting only that portion of semispinalis innervated by $\mathrm{C} 3$, that cause headache. The C2-3 zygapophysial joint is the only structure innervated by the third occipital nerve that could possibly be a source of chronic pain. Therefore, we believe that third occipital nerve blocks are adequately selective for painful disorders of the C2-3 zygapophysial joints.

We elected to use nerve blocks rather than direct joint blocks because, technically, they are easier to perform and are less painful for the patient. Zygapophysial joint blocks involve a troublesome insertion of needles, and require screening in two orthogonal planes. Another limitation is that, in the case of markedly degenerated joints, it may not always be possible to introduce a needle into the eroded joint cavity. Moreover, although joint blocks might appear to be more selective for joint disorders, there is no guarantee that local anaesthetic, injected intra-articularly, remains within a zygapophysial joint cavity. Any leakage outside the joint compromises the selectivity of the block. For this reason we do not believe C2-3 joint blocks are necessarily superior to third occipital nerve blocks as a screening procedure for pain from these joints.

The procedure we used is notably free of risks or major side effects. There are no major structures in the region injected. The vertebral artery lies ventral to 
zygapophysial joints, and so is protected from inadvertent puncture, so long as a posterior approach to the third occipital nerve is used. The spinal cord lies well medial to the target site for the local anaesthetic blocks, and so is not at risk, but it is to ensure that needles are not deflected towards the cord that repeated fluoroscopic screening should be used to monitor the progress of the needle. Similarly, penetration of the epidural space is avoided by directing the course of the needle strictly towards the zygapophysial joint. There should be no risk of the anaesthetic tracking into the epidural space, so long as the ligamentum flavum is intact, for this structure seals off the epidural space from the posterior muscular compartment into which the anaesthetic is injected.

Otherwise, those precautions appropriate to any procedure involving the injection of local anaesthetics, need to be taken. The syringe should be drawn back prior to injection to avoid inadvertent intravascular injection into an intra-muscular vein, and the operator should be fully prepared to deal with the consequences of systemic injection or the rare allergic reaction to local anaesthetic.

There is, however, one possible side-effect peculiar to injections in the upper cervical region, and this the complaint of light-headedness, dizziness or slight ataxia. It is due to interference by the local anaesthetic with the proprioceptive afferents from the upper cervical muscles involved in the tonic neck reflex, and has been discussed in previous studies of upper cervical blocks. ${ }^{14}$ It was reported regularly by our patients who, indeed, were forewarned of the possibility. The effect never outlasted the duration of action of the local anaesthetic used, and usually waned well before the pain relief ceased. It was never serious or incapacitating. By forewarning patients, and coaching them to rely more on visual cues for balance (by concentrating on the horizontal when walking), and reassuring that it is only a temporary effect, this side effect is easily tolerated.

Whereas third occipital nerve blocks can be used to demonstrate that a C2-3 zygapophysial joint is the source of pain, these blocks, per se, do not reveal its actual cause. However, the causative pathology, in our cases, was most likely traumatic arthropathy or degenerative joint disease. Patients 1, 3, 6 and 7 all had histories of recent injuries to the neck, and patient 4 had a history of epilepsy since childhood that involved frequent falls. Thus, all of these patients could be viewed as possibly having sustained an injury to a C2-3 zygapophysial joint. Patient 2 had a history of diffuse degenerative disease of the spine, and it seemed not inappropriate that, as part of this disease, her C2-3 joints were involved.

Analysis of the clinical features of our patients failed to reveal any feature that might be construed as pathognomonic of third occipital headache or that might be used as a specific indication for third occipital nerve blocks. Although restricted neck movements and zygapophysial tenderness were adopted as putatative diagnostic signs, these features occurred in patients who failed to respond to adequate blocks of the third occipital nerve. Furthermore, plain radiographs of the neck revealed no feature in any of our patients that could be construed as indicative of C2-3 arthropathy. Thus, the only diagnostic feature of third occipital headache is positive response to third occipital nerve blocks, and it is our suggestion that these blocks should be performed whenever an alternative diagnosis cannot be confirmed and when third occipital headache might be suspected in the differential diagnosis of occipital pain.

Whereas we concluded that those patients who responsed to third occipital nerve blocks were suffering pain stemming from their C2-3 zygapophysial joints, this diagnosis was excluded in the three patients who did not respond. The associated features of nausea, vomiting and photophobia described by patient 10 allowed us to endorse the diagnosis of common migraine, and accordingly, it is not surprising that he did not respond to cervical nerve blocks. Patients 8 and 9 did not have features that permitted a diagnosis of migraine to be made with any certainty, but in patient number 8 migraine was considered the most likely differential diagnosis, and he, like patient 10 , was referred for further neurological management. The limitations of neck movements described by patient 9 still strongly suggested a cervical cause for his headache, but his failure to respond to third occipital and $\mathrm{C} 2$ ganglion blocks excluded a source of pain in the territories of these nerves, and he was referred for further investigation of his headaches and neck pain.

The principal aim of our report has been to endorse the concept of headache mediated by the third occipital nerve and stemming from the C2-3 zygapophysial joints, and to describe a means of objectively screening for and confirming this diagnosis. It was not our intention to address the issue of treatment, for this is still being evaluated. However, to assuage any lingering doubts about our proposed concept, we offer a brief summary of the therapeutic responses of our patients.

The patients have variously been treated by several techniques. These include intra-articular injections of steroids, cryocoagulation and radiofrequency coagulation of the third occipital nerve, and even open neurectomy. When used, each of these techniques provided total and sustained relief from headache. The confounding issue, however, has been the longevity of response that we have attained. Steroids have worked 
for periods of between 2 weeks and 4 months. Cryocoagulation has lasted between three and six weeks, while radiofrequency coagulation has produced relief in excess of 3 months, and has lasted 12 months in one case. Open neurectomy has achieved the longest responses, so far, of 18 and 24 months.

We offer this summary of therapy, however, not to recommend any particular technique, but to illustrate that, having made the diagnosis of third occipital headache stemming from a C2-3 zygapophysial joint, treatment directed at either the joint or its nerve supply succeeded in producing relief. The recurrence of pain is the problem, but we do not interpret it as an indictment of the diagnosis, but rather as reflecting the limitations of the therapeutic techniques used. Steroids may not be applicable in arthropathy that is perhaps not inflammatory, and neurotomy is compromised by the eventual regeneration of the nerve. Our further studies are directed at refining the indications and optimal application of these techniques.

With respect to open neurectomy, while this appeared a legitimate option in two of our early patients and was effective in relieving their headache, one of them developed neuroma pain that eventually had to be treated by $\mathrm{C} 3$ rhizotomy. It is because of the development of iatrogenic neuromata that we advise against using third occipital neurectomy until adequate means of combating neuroma formation are devised.

It is perhaps remarkable that we identified seven patients with third occipital headache in a consecutive series of ten patients, but we point out that this was not due to any preselection on our part, and rather, probably reflects the referral pattern to our Pain Clinic at the time of the study. However, this high incidence may, alternatively, reflect an actual high incidence in the community of a condition that has remained unrecognised by specialists dealing with headache, and perhaps misdiagnosed as tension headache. It is for this reason, and lest such patients continue to remain unrecognised, that we report the concept of third occipital headache and a means for its objective diagnosis.

In this context, third occipital headache must be viewed as only one of the possible differential diagnoses of headaches of cervical origin. As mentioned in the introduction, arthritis of the C1-2 joints is another possibility. However, at present, there are no established, validated clinical clues that might be used by a practitioner to determine beforehand which patients will respond to third occipital, as opposed to $\mathrm{Cl}-2$, or other, blocks. We suggest only that a high degree of suspicion be maintained in patients with occipital pain of unknown origin, and advise that an armamentarium of techniques is available to pursue the diagnosis. Descriptions of techniques to block the lat- eral atlanto-axial joints, ${ }^{9}$ the $\mathrm{C} 2$ ganglion, ${ }^{14}$ and the lower cervical dorsal rami ${ }^{13}$ are available in the literature. To these we now add the technique for third occipital nerve blocks.

\section{References}

${ }^{1}$ Ad Hoc Committee on Classification of Headache. Classification of headache. JAMA 1962;179:717-8.

${ }^{2}$ Adams RD. Headache. In: Petersdorf RG, Adams RD, Braunwald E, Isselbacher KJ, Martin JB, Wilson JD, eds. Harrison's Principles of Internal Medicine. 10th ed. New York: MiGraw-Hill, 1983;Ch 3:15-25.

${ }^{3}$ Edmeads J. Headaches and head pains associated with diseases of the cervical spine. Med Clin North Am 1978;62:533-44.

${ }^{4}$ Friedman AP. Headache. In: Baker AB, Baker LH, eds. Clinical Neurology. Vol 2. Philadelphia: Harper and Row, 1983;Ch 13:1-50.

${ }^{5}$ Lance JW. Mechanism and Management of Headache. 4th ed. London: Butterworths, 1982.

${ }^{6}$ Wilkinson M. Symptomatology. In: Wilkinson M, ed. Cervical Spondylosis. 2nd ed. London: Heinemann, 1971;Ch 4:59-67.

${ }^{7}$ Brain L. Some unsolved problems of cervical spondylosis. Br Med J 1963;1:771-7.

${ }^{8}$ Fournier AM, Rathelot P. L'arthrose atlo-odontoidienne. Presse Medicale 1960;68:163-5.

${ }^{9}$ Ehni G, Benner B. Occipital neuralgia and the Cl-2 arthrosis syndrome. $J$ Neurosurg 1984;61:961-5.

${ }^{10}$ Mestdagh H. Morphological aspects and biomechanical properties of the vertebroaxial joint (C2-C3). Acta Morphol Neerlando-Scand 1976;14:19-30.

${ }^{11}$ Trevor-Jones R. Osteoarthritis of the paravertebral joints of the second and third cervical vertebrae as a cause of occipital headache. S Afr Med J 1964;38:392-4.

${ }^{12}$ Maigne R,. Signes cliniques des cephalees cervicales: leur traitement. Medecine et Hygiene 1981;39:1174-85.

${ }^{13}$ Bogduk N. The clinical anatomy of the cervical dorsal rami. Spine 1982;7:319-30.

${ }^{14}$ Bogduk N. Local anaesthetic blocks of the second cervical ganglion. A technique with application in occipital headache. Cephalalgia 1981;1:41-50.

${ }^{15}$ Kerr FWL. Structural relation of the trigeminal spinal tract to upper cervical roots and the solitary nucleus in the cat. Exp Neurol 1961;4:134-48.

${ }^{16}$ Escolar J. The afferent connections of the 1st, 2nd, and 3rd cervical nerves in the cat. J Comp Neurol 1948; 89:79-92.

${ }^{17}$ Kerr FWL, Olafson RA. Trigeminal and cervical volleys. Arch Neurol 1961;5:171-8.

${ }^{18}$ Cyriax J. Rheumatic headache. Br Med J 1938;2:1367-8.

${ }^{19}$ Campbell DG, Parsons CM. Referred head pain and its concomitants. J Nerv Ment Dis 1944;99:544-51.

${ }^{20}$ Feinstein B, Langton JBK, Jameson RM, Schiller F. Experiments on referred pain from deep somatic tissues. J Bone Joint Surg 1954;36A:981-97.

${ }^{21}$ McCall IW, Park WM, O'Brien JP. Induced pain referral from posterior lumbar elements in normal subjects. Spine 1979;4:441-6.

${ }^{22}$ Mooney V, Robertson J. The facet syndrome. Clin Orthop 1976;115:149-56. 